\title{
Decrease in Suction
}

National Cancer Institute

\section{Source}

National Cancer Institute. Decrease in Suction. NCI Thesaurus. Code C63254.

Problem associated with the removal of fluid or gas from a body cavity due to decreased suction. 